\title{
Seminal plasma regulates ovarian progesterone production, leukocyte recruitment and follicular cell responses in the pig
}

\author{
S O'Leary, M J Jasper, S A Robertson and D T Armstrong \\ Research Centre for Reproductive Health, Department of Obstetrics and Gynaecology, University of Adelaide, Frome \\ Road, Adelaide SA 5005, Australia \\ Correspondence should be addressed to S O'Leary; Email: sean.oleary@adelaide.edu.au
}

\begin{abstract}
Seminal plasma (SP) acts to influence the uterine endometrium after mating, activating synthesis of embryotrophic cytokines and inflammatory changes that condition the tract for embryo implantation and establishing pregnancy. The objective of this study was to investigate in pigs whether the ovary might also be responsive to SP exposure. Prepubertal gilts were synchronised with exogenous gonadotrophins and received transcervical treatment with pooled boar SP or PBS; then the ovarian tissue was recovered at $34 \mathrm{~h}$ (preovulation) and on days 5 and 9 after treatment. The ovarian response was assessed by measuring ovulation rate, number and size of corpora lutea, ovarian leukocyte populations, progesterone production in vivo, as well as responses of retrieved granulosa cells cultured in vitro. In SP-treated gilts, leukocyte recruitment into the ovarian tissues was increased fourfold at $34 \mathrm{~h}$, with macrophages comprising the most abundant cell lineage. There was no effect of SP on the number of oocytes ovulated; however, the weight of corpora lutea was increased in SP-treated gilts. SP also induced an increase in plasma progesterone content seen from day 5 to at least day 9 after treatment. In addition, granulosa cells and thecal tissue retrieved from preovulatory follicles of SP-treated gilts were more responsive in vitro to growth factor- and gonadotrophin-stimulated cell proliferation and progesterone synthesis. These results suggest that uterine exposure to SP influences immune cell trafficking in the ovary and enhances steroidogenesis in early pregnancy. The effects of SP on ovarian function potentially contribute to reproductive success in the pig.

Reproduction (2006) 132 147-158
\end{abstract}

\section{Introduction}

Conventionally, seminal plasma (SP) is thought to function simply as a transport and survival medium for spermatozoa traversing the female reproductive tract (Mann 1964). This view has been perpetuated by the advent of reproductive technologies, where it is possible to fertilise ova with washed sperm and produce viable embryos resulting in live offspring without exposure of the tract to SP. However, artificial insemination (AI) in livestock species, which often involves extensive dilution of SP, results in fertility and fecundity rates generally lower than those of natural matings (Skjervold 1975, Flowers \& Esbenshade 1993, Tummaruk et al. 2000). Research in rodent species (Robertson \& Sharkey 2001) and pig (Rozeboom et al. 2000, O'Leary et al. 2004) highlights the role of SP in activating the expression of embryotrophic cytokines and preparing the maternal tract for the developing embryo, particularly by facilitating the immune changes required to accommodate pregnancy.
We have previously reported that SP initiates an inflammatory response in pigs characterised by the recruitment and activation of endometrial leukocytes. Leukocyte recruitment is elicited after seminal factors signal uterine epithelial cells to induce expression of a number of pro-inflammatory factors including granulocyte-macrophage colony-stimulating factor (GM-CSF), interleukin-6 (IL-6) and a key regulator of prostaglandin synthesis, cyclooxygenase 2 (COX-2) (O'Leary et al. 2004). Several lines of evidence support the proposal that the effects of SP may extend to affect ovarian function. Seminal components are involved in the mechanism of coitus-induced ovulation in Camelid species (Chen 1985, Paolicchi 1999, Pan et al. 2001, Adams et al. 2005, Ratto et al. 2005), koalas (Johnston et al. 2004) and in pigs, a SP-induced uterine intermediate has been implicated at the time of ovulation (Waberski et al. 1997a,b, 1999). While the mechanisms underlying these ovarian effects are not completely understood, it is reasonable to suggest a contribution due to local inflammatory mediators in 
ovarian responses. Leukocytes and cytokines have been shown to influence ovarian events (Brannstrom \& Norman 1993). In mice, SP exposure has been shown to be associated with increased ovarian leukocyte recruitment (Gangnuss et al. 2004) with the processes of ovulation and luteinisation exhibiting characteristics reminiscent of an acute inflammatory response in both participating cell types and the chemical mediators involved (Espey 1994). The role of leukocyte populations in the porcine ovary is presently unknown, but studies showing similarities in rodents, humans and other livestock species (Brannstrom \& Norman 1993, Brannstrom et al. 1994, Lawler et al. 1999, Van der Hoek et al. 2000) suggest that leukocyte-mediated mechanisms are common across mammalian species.

Previous studies in pigs have implicated a role for SP in influencing the ovarian function by accelerating the ovulatory process (Waberski et al. 1997a,b, 1999). Using unilateral uterine horn infusions (the Mariensee model), Waberski et al. (1995) demonstrated that native SP advanced ovulation by up to $11 \mathrm{~h}$ in the ipsilateral ovary compared to the contralateral ovary and the activity was attributed to a non-steroidal component (Waberski et al. 1995). However, this study did not examine the effects of SP exposure on the luteal function of the ovary, which is instrumental in the successful progression of early pregnancy. Furthermore, the underlying mechanisms by which seminal factors exert their effects were not examined.

The aim of the present study was to determine whether exposure to SP could alter ovarian function. We hypothesised that leukocyte recruitment in the uterus due to SP exposure extends to the ovary and results in enhanced follicular cell responses to luteinising hormone (LH) with a resulting increase in progesterone secretion during early pregnancy. The experimental approach used in the present study was to give intrauterine SP or PBS infusions in equine chorionic gonadotrophin (eCG)/human chorionic gonadotrophin (hCG)-induced and spontaneously cycling gilts and then assess ovaries for leukocyte localisation in peri-ovulatory follicles and measure corpora lutea $(\mathrm{CL})$ development and plasma progesterone levels. In addition, a series of in vitro experiments were carried out on retrieved ovarian tissue to examine whether prior SP exposure of the tract influences the responsiveness of steroidogenic cells of follicles in vitro.

\section{Materials and Methods}

This study was conducted at The University of Adelaide, Pig and Poultry Production Institute (PPPI) in Roseworthy, Australia. All treatments, housing and retrieval of tissues were approved by The University of Adelaide Animal Ethics Committee. Semen and SP used for this study were provided by SABOR Pty. Ltd (Clare, Australia).

\section{Experimental design}

A cohort of $65 F_{1}$ (landrace $\times$ large white) prepubertal gilts at 24 weeks of age was used to determine the effect of uterine exposure to SP on ovarian function before expected ovulation and on days 5 and 9 post-treatment. Experiment 1 examined ovarian responses to intrauterine SP or PBS in eCG/hCG-synchronised gilts at $36 \mathrm{~h}$ of posthCG, i.e. before expected ovulation. The ovarian tissue was retrieved for immunohistochemical analysis of ovarian leukocyte populations and the follicular cells were collected to investigate the effects of SP exposure on progesterone secretion in vitro. Experiment 2 investigated the effects of intrauterine SP or PBS on corpus luteum function during early pregnancy in the eCG/hCG-synchronised gilts, as determined by serial blood sampling for plasma progesterone measurements during the first 9 days post-treatment. Experiment 3 investigated the effects of intrauterine SP or PBS on ovulation rate and luteal function during early pregnancy as determined by ovarian measurements and plasma progesterone in groups of gilts at autopsy on days 5 and 9 post-treatment and Al.

\section{$S P$ treatment and artificial insemination}

For SP treatment, the full ejaculate minus the gel fraction was collected from eight boars of known fertility following at least 5 days abstinence after a previous collection. The semen was pooled, placed on ice and the SP was collected after centrifugation at $1200 \mathrm{~g}$ at $4{ }^{\circ} \mathrm{C}$ for 20 min. Microscopic assessment (magnification 200X) was undertaken to ensure removal of spermatozoa. Aliquots of SP were placed in $100 \mathrm{ml}$ artificial insemination bottles and stored at $-20{ }^{\circ} \mathrm{C}$ for $2-3$ weeks before use. Cytokine stability at $-20^{\circ} \mathrm{C}$ was checked for transforming growth factor- $\beta$ (TGF- $\beta$ ), with less than $10 \%$ reduction in immunoactivity detected by ELISA (data not shown). PBS was filter-sterilised and stored at $4{ }^{\circ} \mathrm{C}$ until needed. The semen used for Al was from pooled ejaculates of fertile boars in Androhep semen extender (Minitub GmbH, Landshut, Germany) extended to $3 \times 10^{9}$ spermatozoa per Al dose and the same boars were not necessarily used for the collection of SP. Extended semen for artificial insemination was prepared, stored and administered according to the standard Australian Pig Industry protocols employed at SABOR Pty. Ltd and PPPI.

\section{Oestrus synchronisation}

In the following experiments, oestrus was induced in gilts at 24 weeks of age by i.m. injections of 750 IU eCG (Folligon; Intervet, Holland) followed by 500 IU of hCG (Chorulon; Intervet) $72 \mathrm{~h}$ later. Responsiveness to eCG was determined by the observation of increased swelling and redness of vulva. Nose to nose boar contact was 
provided to gilts in experiment 3 at 0900 and $1600 \mathrm{~h}$ daily from day 16 post-hCG to standing oestrus.

\section{Experiment 1: The effect of SP on ovarian responses $34 \mathrm{~h}$ post-treatment}

After eCG/hCG synchronisation of oestrus, ten gilts at 24 weeks of age were randomly allocated to receive $100 \mathrm{ml}$ intrauterine infusion by transcervical catheter (Minitub) of pooled boar SP or PBS approximately $2 \mathrm{~h}$ after hCG injection. The gilts were slaughtered at a commercial abattoir $34 \mathrm{~h}$ after treatment and approximately $6 \mathrm{~h}$ before expected ovulation using this synchronisation protocol. Ovaries were obtained for cell culture and histochemical analysis. One of the gilts was excluded from the experiment due to endometritis with cystic ovaries from within the PBS-treated group. An additional three replicates (4-6 gilts per treatment) were killed at $34 \mathrm{~h}$ post-infusion to provide additional preovulatory follicle data for a total of 16-17 gilts per treatment group at this time point.

\section{Isolation and culture of ovarian cells}

An in vitro culture system was developed to investigate the effects of prior SP exposure on DNA synthesis and progesterone secretion from the ovarian tissues. The protocols used for the isolation of ovarian cells have been previously described (Evans et al. 1981). Briefly, surface follicles on each ovary were counted and their diameters measured with callipers. Preovulatory (size $>6 \mathrm{~mm}$ diameter) follicles were aspirated to recover follicular fluid (FF) and oocyte-cumulus complexes (OCC), using dry $1 \mathrm{ml}$ syringes with 20-gauge 1 inch needles. Pooled FF containing OCCs was delivered into dry $35 \mathrm{~mm}$ Petri dishes for the retrieval of OCCs. All OCCs were transferred to $1.7 \mathrm{ml}$ Eppendorf tubes for fixation and assessment of meiotic status. After OCC recovery, pooled FF from each gilt was transferred to a $1.7 \mathrm{ml}$ Eppendorf tube, weighed to determine FF volume and frozen without centrifugation for FF steroid analyses.

Granulosa cells were isolated from whole follicles from in vivo-treated preovulatory gilts. Eight preovulatory follicles from each gilt were dissected into half and placed in $35 \mathrm{~mm}$ Petri dishes in HEPES-buffered tissue culture medium-199 (HTCM; ICN, Costa Mesa, CA, USA) supplemented with $2 \mathrm{mM}$ sodium pyruvate (Sigma), $100 \mathrm{U} / \mathrm{ml}$ penicillin G (Sigma), $100 \mathrm{mg} / \mathrm{ml}$ streptomycin sulphate (Sigma) and $0.3 \mathrm{mg} / \mathrm{ml}$ polyvinyl alcohol (Sigma). Mural granulosa cells (MGC) were scraped from the follicle wall according to the method of Weiss et al. (1978) and the cells were pooled from eight follicles per gilt.

Pooled MGCs from eight follicles of each gilt were rinsed as cell aggregates without dissociation by centrifugation (500 rpm for $5 \mathrm{~min}$ ) through two washes of HTCM and one wash of bicarbonate-buffered tissue culture medium-199 (BTCM). The final pellet was resuspended in $4 \mathrm{ml}$ and an aliquot was removed for cell counting. Cell suspensions were then diluted with BTCM to provide the desired final cell density and $0.1 \mathrm{ml}$ aliquots of the granulosa cell aggregates were pipetted into duplicate wells of 96-well flat-bottomed tissue culture plates (Falcon, Franklin Lakes, NJ, USA) for culture in BTCM containing $5 \mathrm{IU} / \mathrm{ml}$ hCG (Pregnyl; Organon) or BTCM alone. Dose-response experiments were performed using different concentrations of hCG to determine the dose required to evoke maximal responses in porcine granulosa and thecal cells (data not shown). Cultures were carried out in a humidified atmosphere of $5 \% \mathrm{CO}_{2}$ in air at $39{ }^{\circ} \mathrm{C}$ for $24 \mathrm{~h}$. Cultures were pulselabelled with ${ }^{3} \mathrm{H}$-thymidine during the last $6 \mathrm{~h}$ of culture. Granulosa cell densities ranged from $2 \times 10^{5}$ to $1 \times 10^{6}$ cells per well, or the equivalent of $0.05-0.25$ follicle equivalents $/ 0.25 \mathrm{ml}$ well. Cultures began within $6 \mathrm{~h}$ of slaughter and at the end of each culture, medium was collected and stored at $-20{ }^{\circ} \mathrm{C}$ for the assay of progesterone content.

After scraping MCG from follicle walls, the remaining thecal tissue pieces were cut into quarters, washed through two washes of HTCM and one wash of BTCM and the pieces were distributed into wells of four-well culture plates, with one quarter theca from each of four follicles (one follicular equivalent) allocated per well for in vitro treatments. Cultures were carried out in humidified atmosphere of $5 \% \mathrm{CO}_{2}$ in air at $39^{\circ} \mathrm{C}$ for $24 \mathrm{~h}$ in $1 \mathrm{ml} \mathrm{BTCM}$ with the addition of growth factors and gonadotrophins as described earlier. The medium was then collected and frozen for progesterone assay and the thecal tissue was blotted on a filter paper and weighed to determine the wet weight of tissue per well.

\section{Measurement of DNA synthesis and progesterone secretion}

Incorporation of ${ }^{3} \mathrm{H}$-thymidine (ICN) was measured in granulosa cells as an indication of the degree of DNA synthesis and cellular proliferation. To remove unincorporated isotope, cells were harvested onto a filter mat using a Tomtec Harvester 96 (Tomtec, Hamden, CT, USA). Filter mats were then saturated with scintillation fluid (Amersham) and emission of $\beta$-particles from incorporated ${ }^{3} \mathrm{H}$-thymidine was quantified by a Wallac microbeta counter (Fisons, Leicestershire, UK).

The concentrations of progesterone in plasma, FF and cell culture supernatants were assayed using an RIA kit (Diagnostic Systems Laboratories, Webster, TX, USA). The assay was performed as per manufacturer's recommendations with the exception that the volume of sample was halved and the values were obtained from a 1-150 nM standard curve. The intra assay coefficient of variation was $<10 \%$. 


\section{Immunohistochemistry of ovarian tissue $34 \mathrm{~h}$ after treatment}

Immunohistochemical analysis was performed on the ovarian tissues collected from gilts slaughtered at $34 \mathrm{~h}$ after intrauterine infusion with SP or PBS. A sample of each ovary (comprising approximately one-quarter of the entire ovary and containing at least one preovulatory follicle) was dissected and placed in optimal cutting temperature compound (Tissue-Tek; Sakura Finetek Inc., Torrance, CA, USA), immersion-frozen in liquid nitrogen-cooled isopentane, transported to the laboratory in dry ice and stored at $-70{ }^{\circ} \mathrm{C}$ until further processing. The ovarian tissue was serially cut into $7 \mu \mathrm{m}$ sections, placed on poly-L-lysine-coated slides (Polysine Microslides; Menzel-Glaser, Germany) and allowed to air-dry. Dried sections were fixed in $96 \%$ ethanol for $10 \mathrm{~min}$ at $4{ }^{\circ} \mathrm{C}$, then washed 3 times in $1 \times$ PBS. The sections were blocked with $1 \%$ BSA in PBS for $2 \mathrm{~min}$ and then incubated with primary antibody diluted to $10 \mu \mathrm{g} / \mathrm{ml}$ in $10 \%$ normal pig serum in PBS (PBS-NPS) for $2 \mathrm{~h}$ at $4{ }^{\circ} \mathrm{C}$. Murine monoclonal antibodies reactive with porcine CD45 (MCA1222) and swine leukocyte class II antigen (SLAII; MSA3) were purchased from Serotec (Oxford, UK) and Veterinary Medical Research and Development, Inc. (Pullman, WA, USA) respectively. The sections were washed in PBS and incubated with biotinylated rabbit anti-mouse Ig (Dakopatts, Glostrup, Denmark) in PBS-NPS for $60 \mathrm{~min}$ at room temperature. The sections were then washed in PBS and incubated in horseradish peroxidase-conjugated streptavidin (Dakopatts) in PBS-NPS (30 min, room temperature). Bound antibody was visualised by incubating slides with $0.05 \%$ diaminobenzidine tetrahydrochloride (DAB) (Sigma) in Tris-buffered saline containing $0.1 \%$ hydrogen peroxide (10 min, room temperature). The slides were counterstained with haematoxylin, dehydrated, cleared in Safsolvent (Ajax Chemicals, Sydney, Australia) and mounted in DPX (Ajax Chemicals). The specificity of antibody binding was confirmed by comparison with negative control slides incubated without primary antibody and with isotype-matched control antibodies. The numbers of positively stained leukocytes were quantified in ten randomly selected fields of stroma and thecal tissue, avoiding follicular antrum and granulosa cell regions. Video image analysis was employed using Video Pro software (Leading Edge Software, Adelaide, Australia) with a $10 \times$ objective and $3.3 \times$ photo eyepiece as previously described (Robertson et al. 1996). Data were expressed as 'percent positivity', calculated as the mean area of DAB stain as percentage of the area of total stain in ten fields. Repeated measurements of a single test field validated the precision of this method $(<10 \%$ intra-assay variation).

\section{Experiment 2: The effect of intrauterine SP on corpus luteum function in early pregnancy}

To investigate the effect of intrauterine infusion of SP on ovarian function in early pregnancy, ten gilts were cannulated with ear vein catheters to allow serial blood collections. These gilts received eCG/hCG synchronisation and intrauterine SP or PBS infusions as detailed earlier and in addition, received two AI doses of extended semen, the first $2 \mathrm{~h}$ after treatment and the second on the following morning. All gilts were housed in single stalls for the duration of the experiment to allow serial blood samples to be taken. Nine days after intrauterine treatment, reproductive tracts were collected at slaughter for the analysis of ovarian and embryo development.

\section{Ear vein catheterisation}

To collect serial blood samples for progesterone determination, a non-surgical method of placing a catheter into the jugular vein via an ear vein was employed, as previously described (Virolainen et al. 2005). Catheters were introduced 2-3 days before oestrus synchronisation began and remained in place until the experiment was terminated 10 days after hCG treatment. The ear was disinfected using 5\% hibitane solution (AstraZeneca) in physically immobilised gilts and one of the auricular veins was occluded by digital pressure. A 14-gauge catheter placement unit (Jelco, Critikon, Inc., Tampa, FL, USA) was inserted into the vein. A $1 \mathrm{~m}$ polyvinyl catheter $(1.5 \mathrm{~mm}$ OD $\times 1.0 \mathrm{~mm}$ ID; Citchley Electrical Products, NSW, Australia) was inserted through the placement unit and into the vein to a distance of approximately $0.5 \mathrm{~m}$. After testing patency with a syringe, the catheter was flushed with sterile saline containing $9 \mathrm{~g} / \mathrm{I} \mathrm{EDTA}$ as an anticoagulant and plugged with a blunt 18-gauge needle and cap. The catheter was held in place by adhesive bandage and a protective pouch was used to retain cleanliness of the catheter port. The catheter was filled with sterile anticoagulant between collections and at blood collection, the first $2 \mathrm{ml}$ withdrawn was discarded to avoid dilution of the sample.

\section{Blood sampling and tissue collection}

Blood samples were collected daily for the determination of plasma progesterone concentration in heparincoated blood collection tubes (Vacutainer; BD, Franklin Lakes, NJ, USA) from the time of ear vein catheterization to the end of the experimental period of 9 days posttreatment. Plasma was collected by centrifugation of blood at $1200 \mathrm{~g}$ for $20 \mathrm{~min}$ and stored at $-20^{\circ} \mathrm{C}$.

Reproductive tracts were retrieved within approximately 20 min after slaughter at a commercial abattoir. Whole ovaries were dissected and weighed and the number of large follicles or corpora lutea was counted. Corpora lutea were dissected and weighed and the uterine tracts were trimmed and embryos retrieved 
by three consecutive $20 \mathrm{ml}$ flushes of Dulbecco's modified Eagle's medium into each uterine horn. The methods for embryo retrieval and staining have been previously described (O'Leary et al. 2004).

\section{Experiment 3: The effect of intrauterine SP infusion on corpus luteum development on days 5 and 9 post- treatment after spontaneous oestrus}

After induction of first oestrus with eCG/hCG, a total of 23 gilts were randomly allocated into two groups. Boar stimulation was instigated twice daily from day 15 posthCG and oestrus was determined by lordosis in the presence of a boar or due to backpressure exerted by a stockperson. SP or PBS intrauterine infusion was given either the same afternoon or the morning following oestrus detection. Two standard Al doses of extended semen were given as detailed for experiment 2 . Reproductive tracts were retrieved on days 5 and 9 of post-treatment to determine the effect of uterine exposure to SP on the ovarian and embryo development, as described for experiment 2 .

\section{Statistical analysis}

Values are given as mean \pm S.E.M. After determining if the data were normally distributed using the Shapiro-Wilk test, the effect of treatment on tissue weights, leukocyte abundance and in vitro analyses was analysed using Student's $t$-test for independent samples, or by one-way ANOVA followed by Sidak $t$-test when more than two treatment groups were compared. In experiments 2 and 3 , plasma progesterone data were natural log transformed to achieve normal distribution. Determination of treatment effects was then analysed using the Student's $t$-test on plasma progesterone measurements on days 5 and 9. In experiment 2, plasma progesterone data was analysed by growth curve analysis using a cubic polynomial model for repeated measurements. Statistical significance was inferred when $P<0.05$. Statistical analyses were performed using SPSS 13.0 for Windows (SPSS, Inc., Chicago, IL, USA) and SAS 9.1 (SAS Institute, Inc., Cary, NC, USA).

\section{Results}

Experiment 1: The effect of intrauterine SP infusion on preovulatory ovarian parameters

\section{Follicle size and oocyte status at $34 \mathrm{~h}$ post-treatment}

All the gilts appeared to respond to eCG, as evidenced by swollen and inflamed vulvas and size and preovulatory appearance of follicles $(>6 \mathrm{~mm}$ diameter and hyperaemic) and some animals had commenced ovulation or were near ovulation at the time of sacrifice. There was no significant difference in the proportion of SP-treated gilts ovulating earlier than $34 \mathrm{~h}$ after treatment $(4 / 12,33 \%)$ compared to PBS-treated controls (2/10, $20 \%$ ). The mean volume of preovulatory follicles, as determined by weighing the aspirated $\mathrm{FF}$, was $30 \%$ greater in SP-treated than in PBS-treated gilts, but this difference was not statistically significant $(P=0.14$; Table 1). In addition, mean FF progesterone content was increased threefold in SP-treated gilts, although this did not meet statistical significance $(P=0.29$; Table 1$)$. The majority of follicles retrieved contained oocytes that had either begun or completed meiotic maturation at the time of collection, with no significant difference between treatment groups in the percentage of recovered oocytes at either germinal vesicle breakdown or metaphase II stages of maturation (Table 2).

Effect of intrauterine SP on ovarian leukocytes at $34 \mathrm{~h}$ post-treatment

Ovarian tissue recovered $34 \mathrm{~h}$ post-treatment was assessed histochemically for the abundance of total CD45-positive leukocytes and SLAll-positive cells (activated macrophages and dendritic cells). Staining patterns were comparable for both antibodies with labelled cells distributed throughout the ovarian tissue and accumulating in the thecal and stromal tissues adjacent to the follicles (Fig. 1B and D). Compared with PBS-treated control gilts, the ovarian tissue from SP-treated gilts had fourfold higher CD45-positive leukocyte content $(P=0.001)$. These cells were mainly activated macrophages and/or dendritic cells with threefold increase in SLAll-positive cells in tissues from SP-treated gilts ( $P=0.006$; Fig. 2$)$.

Table 1 Effect of intrauterine infusion with seminal plasma (SP) or PBS on ovarian parameters $34 \mathrm{~h}$ after treatment.

\begin{tabular}{|c|c|c|c|c|c|c|}
\hline & $\begin{array}{l}\text { Incidence of } \\
\text { ovulation }^{\mathbf{a}}\end{array}$ & Ovary weight (g) & $\begin{array}{l}\text { Mean no. of } \\
\text { follicles }\end{array}$ & $\begin{array}{c}\text { Maximum follicle } \\
\text { diameter }(\mathrm{mm})\end{array}$ & $\begin{array}{l}\text { Follicular fluid } \\
\text { volume }(\mu \mathrm{l})\end{array}$ & $\begin{array}{c}\text { Follicular fluid } \\
\text { progesterone } \\
(\mathrm{nmol} / \mathrm{l})\end{array}$ \\
\hline PBS & $3 / 17(17.6 \%)$ & $8.92 \pm 0.74$ & $13.2 \pm 1.6$ & $9.3 \pm 0.6$ & $125 \pm 13$ & $2015 \pm 351$ \\
\hline SP & 5/16 (31.3\%) & $7.70 \pm 0.55$ & $15.6 \pm 1.5$ & $9.1 \pm 0.3$ & $168 \pm 24$ & $7421 \pm 2858$ \\
\hline$N(\mathrm{PBS} / \mathrm{SP})$ & $17 / 16$ & $13 / 13$ & $17 / 16$ & $17 / 16$ & $8 / 8$ & $11 / 12$ \\
\hline$P$ & 0.40 & 0.20 & 0.17 & 0.40 & 0.14 & 0.29 \\
\hline
\end{tabular}

Data are mean \pm S.E.M.

${ }^{a}$ Number (\%) of gilts that had commenced ovulating at $34 \mathrm{~h}$ after treatment. N, Number of gilts; $P$, probability. 
Table 2 Effect of intrauterine infusion with SP or PBS on oocyte retrieval parameters 34 h post-treatment.

\begin{tabular}{|c|c|c|c|c|c|}
\hline & Total follicles aspirated & Total oocytes recovered & $\%$ Oocyte recovery & $\%$ GVBD & $\%$ M II \\
\hline PBS & $9.0 \pm 1.7$ & $7.4 \pm 1.8$ & $80.2 \pm 9.6$ & $92.2 \pm 5.9$ & $84 \pm 10.4$ \\
\hline SP & $8.7 \pm 2.2$ & $6.7 \pm 2.1$ & $60.1 \pm 10.7$ & $96.2 \pm 2.5$ & $97 \pm 2.4$ \\
\hline$N(\mathrm{PBS} / \mathrm{SP})$ & $8 / 7$ & $8 / 7$ & $8 / \overline{7}$ & $4 / \overline{6}$ & $\overline{6} / 7$ \\
\hline$P$ & 0.9 & 0.8 & 0.19 & 0.51 & 0.33 \\
\hline
\end{tabular}

Data are mean \pm s.E.M. per gilt. GVBD, germinal vesicle breakdown; MII, metaphase II.

Effect of intrauterine SP on ovarian follicle cell responses in vitro

DNA synthesis in granulosa cells isolated from preovulatory follicles was measured by pulse labelling with ${ }^{3} \mathrm{H}$-thymidine after culture in the absence or presence of hCG. The granulosa cells from SP-treated gilts showed a strong trend towards increased ${ }^{3} \mathrm{H}$-thymidine incorporation when compared to granulosa cells from PBStreated controls $(P=0.06)$; hCG in vitro has no significant effect in either group (Fig. 3A).

Granulosa cells from SP-treated gilts secreted significantly more progesterone than those of PBS-treated controls when cultured in the presence of hCG $(P=0.024$; Fig. 3B). An in vitro stimulatory effect of hCG was evident in both groups $(P=0.001)$, with no significant in vivo $\times$ in vitro interaction. The pattern of progesterone secretion by thecal tissues was similar to that of granulosa cells, although the secretion rate was only about one-tenth of granulosa cells, with a trend towards increased secretion as a result of hCG treatment that did not reach statistical significance $(P=0.064$; Fig. 3C).

\section{Experiment 2: The effect of intrauterine SP on plasma progesterone in early pregnancy}

To investigate the effect of SP treatment on CL function during early pregnancy, the progesterone content was measured in serial blood samples taken daily from gilts by means of a chronic indwelling ear vein catheter. There was a divergence in the profile of progesterone secretion between treatment groups, with the plasma progesterone concentration of SP-treated gilts approximating 20\% higher than that of PBS-treated controls from day 4 to the completion of the experiment on day 9 $(P=0.0006$; Fig. 4). However, differences in ovarian parameters at autopsy on day 9 , including ovary and $\mathrm{CL}$ weights and $\mathrm{CL}$ number, did not meet statistical significance (Table 3).

\section{Experiment 3: The effect of intrauterine SP on ovarian parameters on days 5 and 9 post-treatment}

To undertake a more detailed investigation of the effect of SP on ovarian function during early pregnancy, ovaries were retrieved from additional gilts on days 5 and 9 of post-treatment. SP treatment did not increase the number of $\mathrm{CL}$, the individual or total weight of $\mathrm{CL}$ or total ovarian weight in either day 5 or day 9 treatment groups.

When day 9 data from experiments 2 and 3 were compared, no effect of experiment was seen, enabling analysis of a larger data set comprising the combined data from experiments 2 and 3 . In this complete data set, SP treatment was seen to significantly increase the total corpora lutea weight when day was considered as a covariate $(P=0.023)$. This was attributed to increases in both the number of $C L$ and the weight of the individual $\mathrm{CL}$, although the effect of SP on neither of these parameters reached statistical significance (Table 3).

The progesterone content of plasma samples recovered at autopsy on days 5 and 9 was also measured. Similar plasma progesterone content was observed in experiments 2 and 3, so the two data sets were combined. When the complete data set was analysed, SP treatment was associated with increased plasma progesterone on both days 5 and 9 post-treatment $(P=0.05$ and 0.02 respectively; Fig. 5$)$. When the data were analysed using day as a covariate, a highly significant effect of SP was observed $(P<0.001)$.

\section{Discussion}

An influence of SP on peri-ovulatory function in the pig has previously been reported with uterine exposure to SP causing advanced ovulation through a reduction in the interval between the LH peak and ovulation (Waberski et al. 1995). The present study aimed to determine whether other peri-ovulatory events including leukocyte infiltration, follicle cell growth and steroidogenesis were accelerated by uterine SP treatment. Although we were unable to detect an effect of intrauterine SP on the incidence or timing of ovulation, the large between-gilt variability in these parameters suggests that a considerably larger number of gilts would be required to formally address this. Nevertheless, several indices of follicle maturation showed a trend towards more advanced development when gilts had been treated $34 \mathrm{~h}$ earlier with SP. While SP-treated gilts tended to yield oocytes at more advanced stages of maturation, the effect was inconclusive as a high proportion of oocytes from preovulatory follicles had resumed meiotic maturation at the time of collection, indicating that an earlier time point might have been more informative. Furthermore, while the mean FF volume was increased by $32 \%$ after SP treatment, there was wide variation 

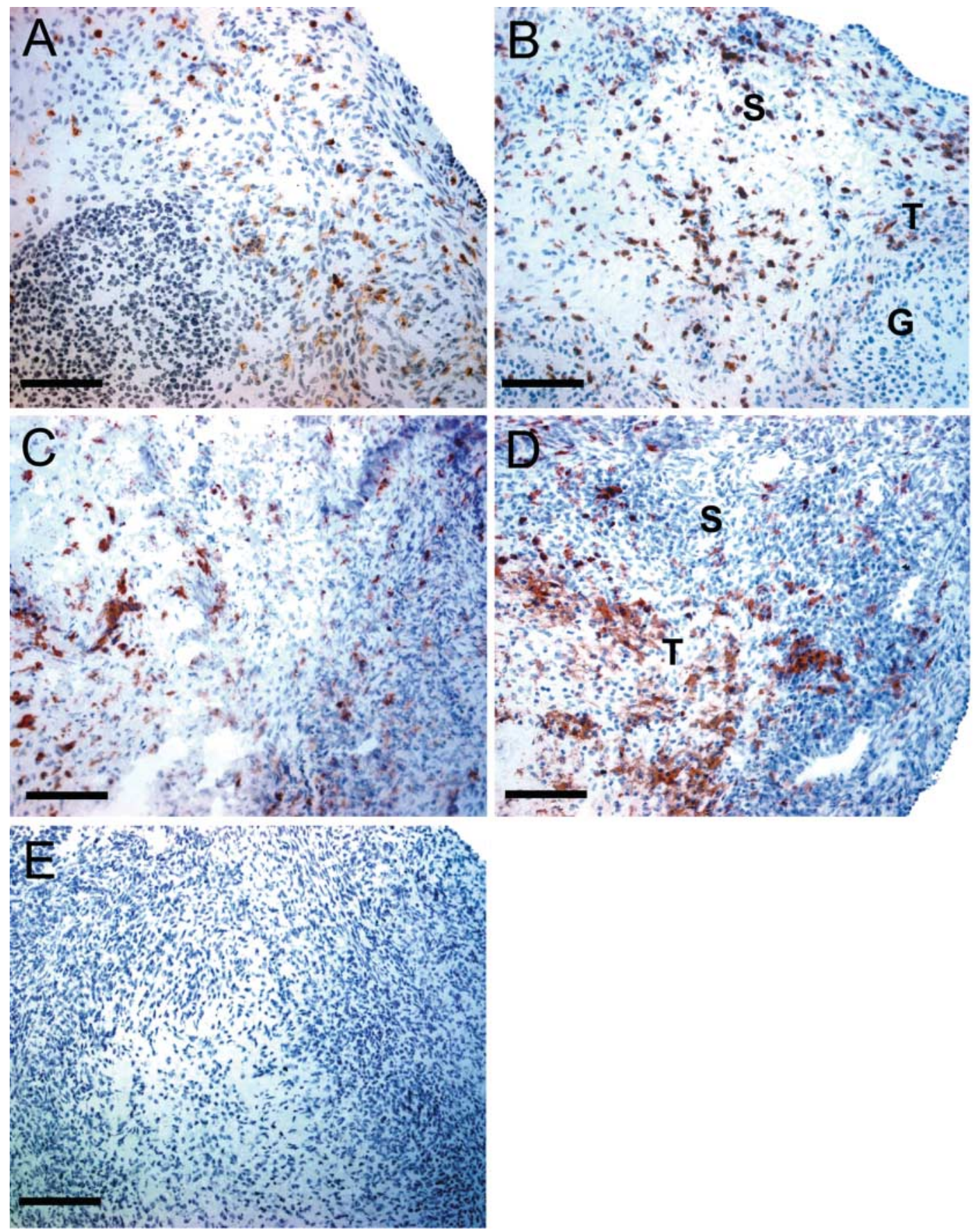

Figure 1 Representative photomicrographs showing immunohistochemical localization of CD45 ${ }^{+}$cells (all leukocytes) and SLAII ${ }^{+}$cells (activated macrophages and dendritic cells) in ovarian sections from PBS-treated (A and C) and seminal plasma (SP)-treated (B and D) gilts compared with negative control (E). G, granulosa; T, theca; S, stroma. Scale bar represents $100 \mu \mathrm{m}$.

across groups and the effect of SP failed to reach statistical significance.

The observations reported in the present study indicate that the effects of intrauterine seminal fluid on the ovary manifest as clear changes in the development and steroidogenic competence of the corpus luteum. The effects of SP treatment are evident as an increased rate of in vitro secretion of progesterone by both granulosa and thecal cells of preovulatory follicles, enhanced responsiveness of both cell types to LH (hCG), and increased DNA synthesis in granulosa cells. The changes in steroidogenesis were accompanied by an increase in ovarian macrophage population, suggesting that inflammatory leukocytes recruited into the ovary just before ovulation may participate in establishing or mediating peri-ovulatory follicle responses to seminal 


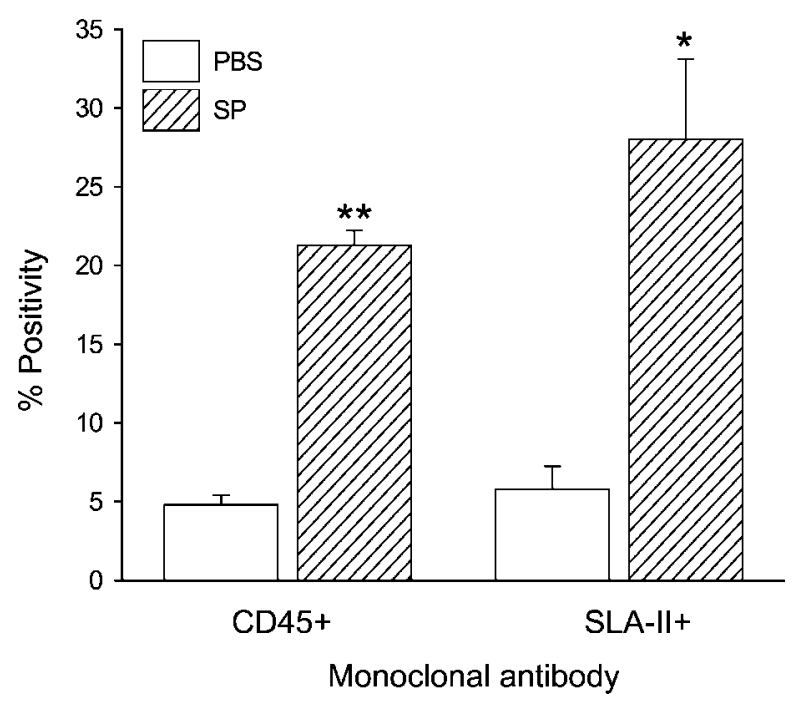

Figure 2 Effect of intrauterine infusion of SP or PBS on the abundance of leukocytes in ovarian tissue retrieved from gilts $34 \mathrm{~h}$ after treatment The number of cells expressing CD45 + or SLAII + was quantified by video image analysis. Data are mean \pm s.E.M.; ${ }^{* *} P=0.001$ and ${ }^{*} P=0.006$.

fluid. The SP effects on progesterone secretion persist into the early luteal phase with increased concentrations of circulating plasma progesterone from days 5 to 9 postovulation, concomitant with an increase in $\mathrm{CL}$ size.

Although there was variation within treatments in the timing of ovulation using hCG/eCG synchronisation, this is unlikely in itself to explain the differences in immune cell trafficking in the ovary $34 \mathrm{~h}$ after treatment. Activated macrophages detected on the basis of their expression of SLA class II were significantly increased in ovarian follicular and stromal tissues after uterine exposure to SP during the pre- and peri-ovulatory period. Our discovery of an approximately fourfold elevation in the abundance of activated macrophages in the thecal and peri-follicular stromal tissue suggests that these cells may have a role in mediating the effects of SP in the ovary. It is likely that these cells and their secretory products influence the architecture and functionality of the vascular stroma and theca tissues of the ovary with direct or indirect effects on granulosa cells. Leukocytes, in particular macrophages, are abundant in the ovary during all stages of the oestrous cycle in pigs (Standaert et al. 1991), whereas in other species, they are likely to have roles in ovulation and corpus luteum formation through their tissue remodelling and cytokine synthesis capabilities. In particular, macrophages have been recognised for their role in inducing progesterone production in granulosa cells in coculture experiments in mice (Kirsch et al. 1981), humans (Halme et al. 1985) and pigs (Standaert et al. 1990) without concomitant granulosa cell proliferation. Two potent cytokines secreted by macrophages, interleukin- 1 and tumour necrosis factor- $\alpha$, have been shown to stimulate both progesterone and prostaglandin synthesis (Nakamura et al. 1990, Kokia
(A)

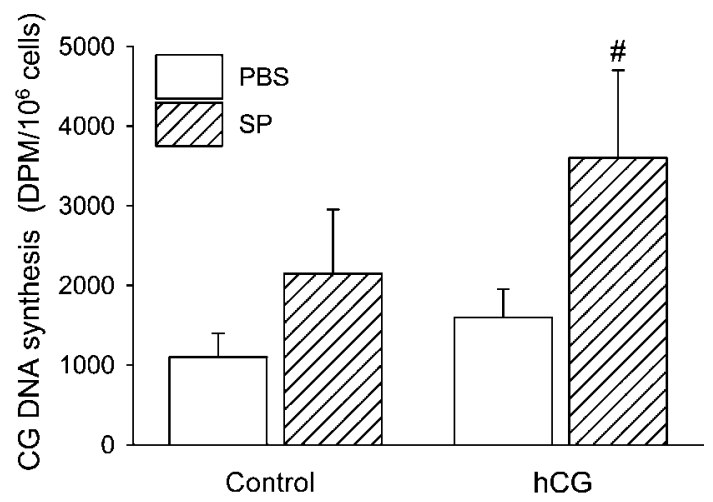

(B)

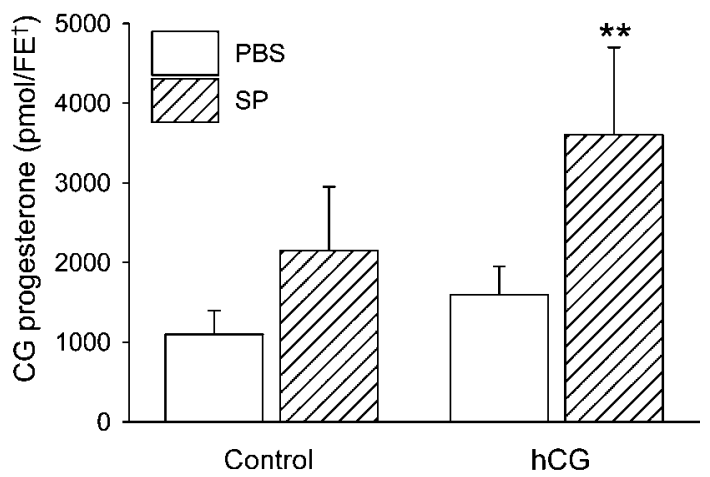

(C)

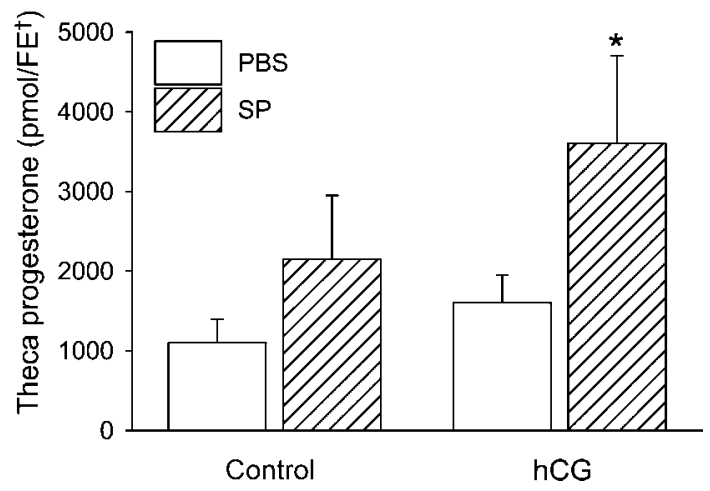

Figure 3 DNA synthesis (A) and progesterone secretion (B) in cultured granulosa cells and thecal tissue $(\mathrm{C})$ retrieved from gilts $34 \mathrm{~h}$ after intrauterine infusion of SP or PBS. Cells were cultured in medium alone, or with $5 \mathrm{IU} / \mathrm{ml}$ hCG. Data are mean \pm s.E.M. of untransformed data; $\# P=0.06,{ }^{*} P=0.003,{ }^{*} P=0.01$ between $\mathrm{SP}$ and equivalent $\mathrm{PBS}$ treatment; (PBS, $n=8 ; \mathrm{SP}, n=7$ ). The effects of treatment were evaluated on natural log transformed data followed by Student's $t$-test (SPSS 13.0). tFE, follicular equivalent.

et al. 1992, Watanabe et al. 1993, Brannstrom et al. 1994, 1995, Roby et al. 1999) and these may interact with other macrophage-derived factors to fine-tune gonadotrophin regulation of corpus luteum function and demise (Wuttke et al. 1997). In vitro experiments from human granulosa cells further implicate cytokines originating from ovarian cells in promoting proliferation and/or functional activation of steroidogenic cells (Jasper et al. 1996). 


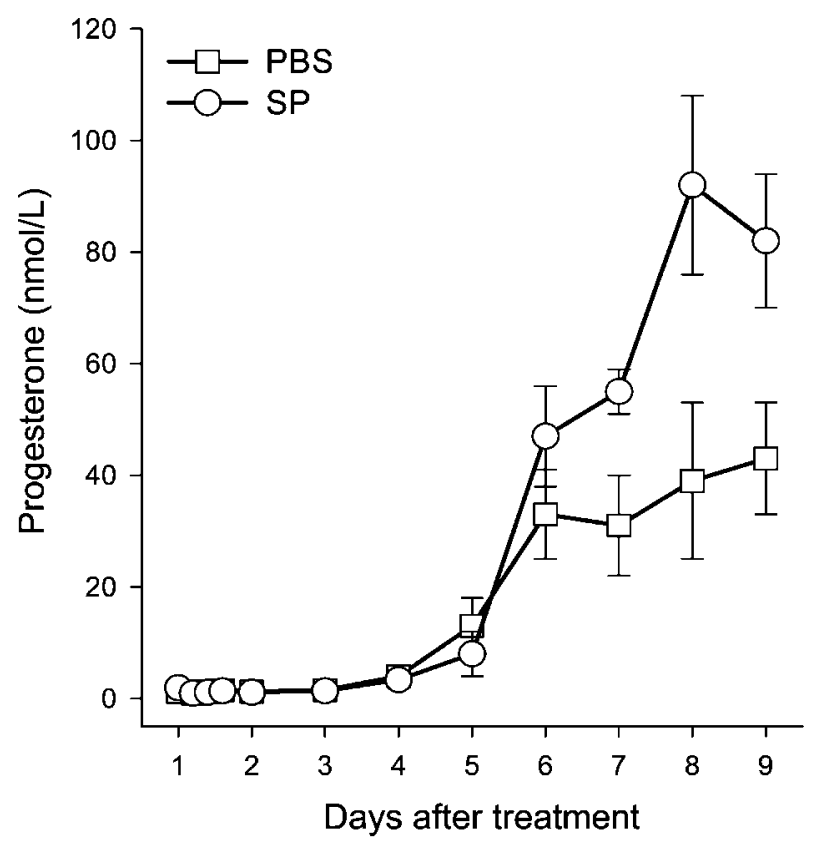

Figure 4 Effects of intrauterine infusion of SP or PBS on plasma progesterone concentrations in gilts from $30 \mathrm{~h}$ to 9 days after SP or PBS treatment. Data are mean \pm s.E.M. of the untransformed data. The effect of treatment was evaluated using growth curve analysis of natural log transformed data (SAS 9.1).

One interesting possibility under present investigation is that SP-mediated increases in macrophage abundance or function programme an increase in sensitivity to gonadotrophin hormones via changes in $\mathrm{LH}$ receptor or steroidogenic enzyme expression. Any change must be preserved ex vivo, since the increased responsiveness of granulosa cells to hCG in vitro after uterine exposure to SP occurred despite the absence of macrophages in the in vitro experiments. Granulosa cells were recovered prior to ovulation and hence were essentially free of contaminating leukocytes.

Synthesis of progesterone by the corpus luteum in early pregnancy is essential for implantation and embryo survival and the kinetics of the rise in progesterone is an important factor in determining embryo viability.

Table 3 Effect of intrauterine infusion with SP or PBS on weight of ovaries and corpora lutea and number of corpora lutea in gilts on days 5 and 9 post-treatment.

\begin{tabular}{lcccc}
\hline & & Ovary weight & Number of $\mathbf{C L}$ & CL weight* \\
\hline Day 5 & PBS $(n=4)$ & $6.9 \pm 1.41$ & $13.5 \pm 1.44$ & $0.34 \pm 0.07$ \\
& SP $(n=6)$ & $8.3 \pm 1.14$ & $14.33 \pm 0.71$ & $0.43 \pm 0.09$ \\
$P$-value & & 0.46 & 0.58 & 0.54 \\
Day 9 & PBS $(n=10)$ & $8.93 \pm 1.45$ & $12.8 \pm 0.73$ & $0.42 \pm 0.03$ \\
& SP $(n=11)$ & $9.15 \pm 0.89$ & $14.33 \pm 1.43$ & $0.47 \pm 0.03$ \\
$P$-value & & 0.89 & 0.39 & 0.36
\end{tabular}

Data are mean \pm S.E.M.; data are combined for gilts sacrificed on day 9 after treatment in experiments 2 and 3 (PBS, $n=10 ; \mathrm{SP}, n=11$ ). $* P=0.023$; the effect of treatment was evaluated with the day is considered as a covariate (SPSS 13.0).

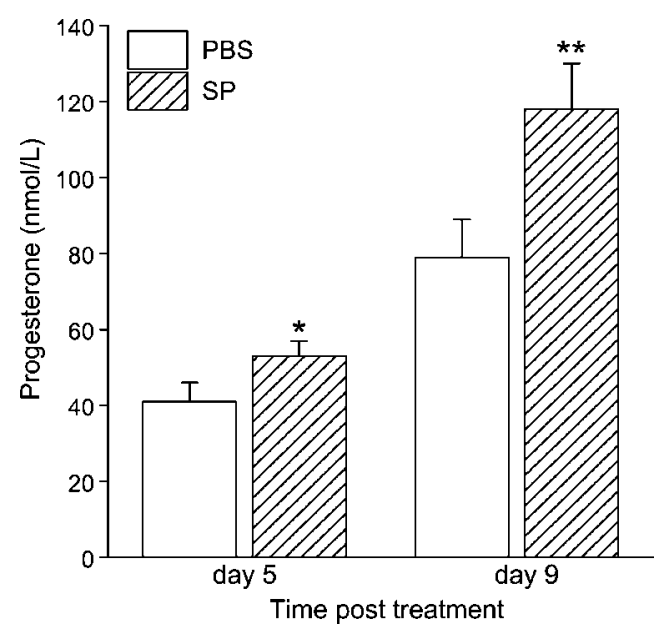

Figure 5 Effects of intrauterine infusion of SP or PBS on plasma progesterone concentrations on days 5 and 9 after SP or PBS treatment. Data are mean \pm S.E.M. of the untransformed data. Data are combined for gilts in experiments 2 and 3 (PBS, $n=10 ;$ SP, $n=11$ ). The effect of treatment was evaluated on natural log transformed data by Student's t-test (SPSS 13.0). $* P=0.05, * * P=0.02$.

Differences in embryo survival have been related to changes in the plasma progesterone levels in early pregnancy in sheep (Ashworth et al. 1989) and gilts (Jindal et al. 1996). Nutritionally induced upregulation of progesterone early in pregnancy results in improved embryonic survival (Jindal et al. 1997a, Almeida et al. 2000). The effect is likely to be due to the influence of progesterone in uterine tissues and the induction of endometrial receptivity via direct and indirect effects on uterine-derived embryotrophic growth factors (Robertson 2000). Furthermore, progesterone may have a direct effect on the ovary, indicated by an experiment showing that exogenous progesterone injected intramuscularly $24 \mathrm{~h}$ before expected ovulation reduces the duration of ovulation by approximately $5 \mathrm{~h}$ in pigs (Duanyai \& Srikandakumar 1998). This presumably increases synchrony within the cohort of developing embryos, thereby potentially improving implantation success (Dzuik 1987).

An effect of SP on ovarian progesterone synthesis has not been previously reported, to our knowledge, in any species. The increase in plasma progesterone due to SP treatment begins around day 5 till about day 9, the profile of which differs from the peri-ovulatory rises seen in the nutritional studies (Jindal et al. 1997b, Almeida et al. 2000). Whether the elevated progesterone secretion, elicited by intrauterine SP exposure, has downstream effects resulting in increased litter sizes remains to be seen. In our previous study (O'Leary et al. 2004), we showed that SP treatment is associated with increased numbers of viable embryos and a change in the embryo development trajectory. This was linked with altered patterns of uterine cytokine expression and an increased abundance of endometrial leukocytes that occurred not 
just during the acute response to insemination, but persisted for at least 9 days into the preimplantation phase. Others have also reported that SP treatment can reduce embryo mortality and increase synchrony of embryo development in pigs (Waberski et al. 1997a). The present study suggests that this persisting effect over the course of early pregnancy might partly be the consequence of elevated local progesterone, which could act to differentially regulate several progesterone-responsive uterine parameters (Hunt et al. 1997) including the observed altered cytokine expression (O'Leary et al. 2004).

The experiments in this present study can be integrated with previously reported observations to provide insight into how SP may influence ovarian function after mating and to speculate upon how seminal constituents might signal to the ovary. While the active factors in boar semen are not yet identified, studies in mice show that TGF- $\beta$ is the key active constituent (Tremellen et al. 1998) and TGF- $\beta$ is also present in abundance in boar semen (SO'Leary unpublished observations). While it is difficult to envisage how seminal proteins could directly access the ovary, it seems more reasonable to postulate that inflammatory mediators induced in the uterus after insemination might be transmitted in an indirect pathway. These uterine mediators potentially include the proinflammatory cytokines GM-CSF and IL- 6 synthesised in the endometrium after mating (O'Leary et al. 2004), but again it seems unlikely that uterine cytokines could access and exert effects distally in the ovary.

A more likely candidate for a uterine-derived ovarian signal is prostaglandin $\mathrm{E}_{2}\left(\mathrm{PGE}_{2}\right)$. COX-2, an enzyme that catalyses the formation of $\mathrm{PGE}_{2}$ (Jones et al. 1997) is upregulated in the uterus in response to uterine exposure to SP (O'Leary et al. 2004). Prostaglandins produced in the uterus have been shown previously to be transported to the ovary via the uterine-ovarian counter current mechanism (Krzymowski et al. 1989), where their availability to the theca cells would be enhanced by increased vascularity of the thecal layer in the preovulatory follicle. Moreover, once prostaglandin has been transported to the ovary, it is likely to stimulate further production of follicular prostaglandins and maintain higher levels via a positive feedback mechanism (Armstrong 1981).

The role of prostaglandins in preovulatory follicular function has been described in prepubertal gilts synchronised with eCG and hCG (Tsang et al. 1979, Ainsworth et al. 1980, Evans et al. 1983). Levels of $\mathrm{PGE}_{2}$ in FF were observed to peak at around $36 \mathrm{~h}$ post-hCG in the follicle (Tsang et al. 1979). An inverse relationship of progesterone to oestrogen was observed at the time of $\mathrm{PGE}_{2}$ peak (Ainsworth et al. 1980) and the theca cells were found to be the predominant follicular source of $\mathrm{PGE}_{2}$ compared to the granulosa cells (Evans et al. 1983). These observations, together with our previous finding of upregulation of endometrial COX-2 by SP, support the proposal that uterine-derived $\mathrm{PGE}_{2}$ may be the active intermediary in accelerating the follicular events, which culminate in ovulation followed by corpus luteum development. The increased proliferative responses and progesterone production in granulosa cells retrieved from SP-treated gilts observed in the present study are consistent with a conditioning effect of higher levels of $\mathrm{PGE}_{2}$ leading to enhanced responses of these cells to hCG treatment in vitro compared to their PBS-treated counterparts. Through its capacity to induce chemokine expression and modulate the behaviour of myeloid leukocytes (Jones et al. 1997, Harizi \& Gualde 2005), elevated $\mathrm{PGE}_{2}$ in the ovary could also contribute to the increased macrophage recruitment seen after SP treatment, so an indirect role of $\mathrm{PGE}_{2}$ acting via macrophages is also consistent with this model.

In conclusion, the results of this study show that factors in the SP introduced into the uterus prior to ovulation can influence ovarian function by enhancing follicular cell responses leading to increased progesterone production to cause changes that would facilitate the successful initiation of pregnancy. These effects are likely to be mediated via a semen-uterineovarian communication axis, whereby $\mathrm{PGE}_{2}$ transported by the uterine-ovarian counter current mechanism is a candidate mediator of communication between the uterus and the ovary. Perturbations in the levels of active seminal factors, including the dilution of seminal components characteristic of artificial insemination regimes, are likely to affect uterine and ovarian responses in early pregnancy and influence the rate of embryo survival and developmental competence in the pig. Reproductive management involving strategies to include exposure to seminal fluid or its active constituents has the potential to maximise reproductive outcomes after artificial insemination in the pig industry.

\section{Acknowledgements}

The authors wish to thank R R C Kamai for assistance with immunohistochemical analysis, L Ritter and S Scott for assistance with tissue collections, ovarian cell isolation and culture, Dr R Gilchrist for assessment of meiotic state of oocytes, L Yelland and K Willson from the Department of Public Health, University of Adelaide for statistical advice and the staff at PPPI piggery, Roseworthy, Australia for assistance with animal treatments. This study was supported by Australian Pork Limited, NHMRC (Australia) and Canadian Institute of Health Research.

\section{References}

Adams GP, Ratto MH, Huanca W \& Singh J 2005 Ovulation-inducing factor in the seminal plasma of alpacas and llamas. Biology of Reproduction 73 452-457.

Ainsworth L, Tsang BK, Downey BR, Marcus GJ \& Armstrong DT 1980 Interrelationships between follicular fluid steroid levels, gonadotropic stimuli, and oocyte maturation during preovulatory development of porcine follicles. Biology of Reproduction 23 621-627. 
Almeida FR, Kirkwood RN, Aherne FX \& Foxcroft GR 2000 Consequences of different patterns of feed intake during the estrous cycle in gilts on subsequent fertility. Journal of Animal Science $\mathbf{7 8}$ 1556-1563.

Armstrong DT 1981 Prostaglandins and follicular functions. Journal of Reproduction and Fertility 62 283-291.

Ashworth CJ, Sales DI \& Wilmut I 1989 Evidence of an association between the survival of embryos and the periovulatory plasma progesterone concentration in the ewe. Journal of Reproduction and Fertility 87 23-32.

Brannstrom M \& Norman RJ 1993 Involvement of leukocytes and cytokines in the ovulatory process and corpus luteum function. Human Reproduction 8 1762-1775.

Brannstrom M, Norman RJ, Seamark RF \& Robertson SA 1994 Rat ovary produces cytokines during ovulation. Biology of Reproduction 50 88-94.

Brannstrom M, Bonello N, Wang LJ \& Norman RJ 1995 Effects of tumour necrosis factor alpha (TNF alpha) on ovulation in the rat ovary. Reproduction, Fertility, and Development 7 67-73.

Chen BX 1985 Semen-induced ovulation in the bactrian camel (Camelus bactrianus). Journal of Reproduction and Fertility 74 335-339.

Duanyai S \& Srikandakumar A 1998 Premature elevation of progesterone shortens duration of ovulation in PMSG/hCG-treated prepubertal gilts. Theriogenology 50 433-443.

Dzuik PJ 1987 Embryonic loss in the pig: an enigma. Proceedings of the Inaugural conference of Australian Pig Science Association, pp. 28-39, NSW: Albury.

Espey LL 1994 Current status of the hypothesis that mammalian ovulation is comparable to an inflammatory reaction. Biology of Reproduction $\mathbf{5 0} 233-238$.

Evans G, Dobias M, King GJ \& Armstrong DT 1981 Estrogen, androgen, and progesterone biosynthesis by theca and granulosa of preovulatory follicles in the pig. Biology of Reproduction 25 673-682.

Evans G, Dobias M, King GJ \& Armstrong DT 1983 Production of prostaglandins by porcine preovulatory follicular tissues and their roles in intrafollicular function. Biology of Reproduction $\mathbf{2 8}$ 322-328.

Flowers WL \& Esbenshade KL 1993 Optimizing management of natural and artificial matings in swine. Journal of Reproduction and Fertility 48 217-228.

Gangnuss S, Sutton-McDowall ML, Robertson SA \& Armstrong DT 2004 Seminal plasma regulates corpora lutea macrophage populations during early pregnancy in mice. Biology of Reproduction $\mathbf{7 1}$ $1135-1141$.

Halme J, Hammond MG, Syrop CH \& Talbert LM 1985 Peritoneal macrophages modulate human granulosa-luteal cell progesterone production. Journal of Clinical Endocrinology and Metabolism 61 912-916.

Harizi H \& Gualde N 2005 The impact of eicosanoids on the crosstalk between innate and adaptive immunity: the key roles of dendritic cells. Tissue Antigens 65 507-514.

Hunt JS, Miller L, Roby KF, Huang J, Platt JS \& DeBrot BL 1997 Female steroid hormones regulate production of pro-inflammatory molecules in uterine leukocytes. Journal of Reproductive Immunology 35 87-99.

Jasper MJ, Brannstrom M, Olofsson JI, Petrucco OM, Mason H, Robertson SA \& Norman RJ 1996 Granulocyte-macrophage colonystimulating factor: presence in human follicular fluid, protein secretion and mRNA expression by ovarian cells. Molecular Human Reproduction 2 555-562.

Jindal R, Cosgrove JR, Aherne FX \& Foxcroft GR 1996 Effect of nutrition on embryonal mortality in gilts: association with progesterone. Journal of Animal Science 74 620-624.

Jindal R, Cosgrove JR \& Foxcroft GR 1997a Progesterone mediates nutritionally induced effects on embryonic survival in gilts. Journal of Animal Science 75 1063-1070.

Jindal R, Cosgrove JR \& Foxcroft GR 1997b Progesterone mediates nutritionally induced effects on embryonic survival in gilts. Journal of Animal Science 75 1063-1070.
Johnston SD, O'Callaghan P, Nilsson K, Tzipori G \& Curlewis JD 2004 Semen-induced luteal phase and identification of a $\mathrm{LH}$ surge in the koala (Phascolarctos cinereus). Reproduction 128 629-634.

Jones RL, Kelly RW \& Critchley HO 1997 Chemokine and cyclooxygenase-2 expression in human endometrium coincides with leukocyte accumulation. Human Reproduction 12 1300-1306.

Kirsch TM, Friedman AC, Vogel RL \& Flickinger GL 1981 Macrophages in corpora lutea of mice: characterization and effects on steroid secretion. Biology of Reproduction 25 629-638.

Kokia E, Hurwitz A, Ricciarelli E, Tedeschi C, Resnick CE, Mitchell MD \& Adashi EY 1992 Interleukin-1 stimulates ovarian prostaglandin biosynthesis: evidence for heterologous contact-independent cellcell interaction. Endocrinology 130 3095-3097.

Krzymowski T, Stefanczyk-Krzymowska S \& Koziorowski M 1989 Counter current transfer of PGF2 alpha in the mesometrial vessels as a mechanism for prevention of luteal regression in early pregnancy. Acta Physiology Poland 40 23-34.

Lawler DF, Hopkins J, Watson ED, Penny LA, Armstrong D, Bramley TA, Webb R \& Collins RA 1999 Immune cell populations in the equine corpus luteum throughout the oestrous cycle and early pregnancy: an immunohistochemical and flow cytometric study. Journal of Reproduction and Fertility 117 281-290.

Mann T 1964 The Biochemistry of Semen and the Male Reproductive Tract, 1st edn, pp. 39-41. London: Methuen \& Co Ltd.

Nakamura Y, Kato H \& Terranova PF 1990 Interleukin-1 alpha increases thecal progesterone production of preovulatory follicles in cyclic hamsters. Biology of Reproduction 43 169-173.

O'Leary S, Jasper MJ, Warnes GM, Armstrong DT \& Robertson SA 2004 Seminal plasma regulates endometrial cytokine expression, leukocyte recruitment and embryo development in the pig. Reproduction 128 237-247.

Pan G, Chen Z, Liu X, Li D, Xie Q, Ling F, Fang L, Chen BX, Yuen ZX \& Pan GW 2001 Isolation and purification of the ovulation-inducing factor from seminal plasma in the bactrian camel (Camelus bactrianus). Theriogenology 55 1863-1879.

Paolicchi F 1999 Biological activity of the seminal plasma of alpacas: stimulus for the production of LH by pituitary cells. Animal Reproduction Science 54 203-210.

Ratto MH, Huanca W, Singh J \& Adams GP 2005 Local versus systemic effect of ovulation-inducing factor in the seminal plasma of alpacas. Reproductive Biology and Endocrinology 329.

Robertson SA 2000 Control of the immunological environment of the uterus. Reviews of Reproduction 5 164-174.

Robertson SA \& Sharkey DJ 2001 The role of semen in induction of maternal immune tolerance to pregnancy. Seminars in Immunology 13 243-254.

Robertson SA, Mau VJ, Tremellen KP \& Seamark RF 1996 Role of high molecular weight seminal vesicle proteins in eliciting the uterine inflammatory response to semen in mice. Journal of Reproduction and Fertility 107 265-277.

Roby KF, Son DS \& Terranova PF 1999 Alterations of events related to ovarian function in tumor necrosis factor receptor type I knockout mice. Biology of Reproduction 61 1616-1621.

Rozeboom KJ, Troedsson MHT, Hodson HH, Shurson GC \& Crabo BG 2000 The importance of seminal plasma on the fertility of subsequent artificial inseminations in swine. Journal of Animal Science 78 443-448.

Skjervold H 1975 Comparison of litter size by use of natural and by artificial mating. Zeitschrift für Tierzüchtung und Züchtungs biologie 92 252-259.

Standaert FE, Chew BP \& Wong TS 1990 Influence of blood monocytes and lymphocytes on progesterone production by granulosa cells from small and large follicles in the pig. American Journal of Reproductive Immunology 22 49-55.

Standaert FE, Zamora CS \& Chew BP 1991 Quantitative and qualitative changes in blood leukocytes in the porcine ovary. American Journal of Reproductive Immunology 25 163-168.

Tremellen KP, Seamark RF \& Robertson SA 1998 Seminal transforming growth factor beta1 stimulates granulocyte-macrophage 
colony-stimulating factor production and inflammatory cell recruitment in the murine uterus. Biology of Reproduction 58 1217-1225.

Tsang BK, Ainsworth L, Downey BR \& Armstrong DT 1979 Preovulatory changes in cyclic AMP and prostaglandin concentrations in follicular fluid of gilts. Prostaglandins 17 141-148.

Tummaruk P, Lundeheim N, Einarsson S \& Dalin A-M 2000 Reproductive performance of purebred Swedish Landrace and Swedish Yorkshire sows: II, Effect of mating type, weaning-to-firstservice interval and lactation length. Acta Agriculturae Scandinavica, Section A - Animal Science $\mathbf{5 0} 217-224$.

Van der Hoek KH, Maddocks S, Woodhouse CM, van Rooijen N, Robertson SA \& Norman RJ 2000 Intrabursal injection of clodronate liposomes causes macrophage depletion and inhibits ovulation in the mouse ovary. Biology of Reproduction 62 1059-1066.

Virolainen JV, Love RJ, Tast A \& Peltoniemi OA 2005 Plasma progesterone concentration depends on sampling site in pigs. Animal Reproduction Science 86 305-316.

Waberski D, Sudhoff H, Hahn T, Jungblut PW, Kallweit E, Calvete JJ, Ensslin M, Hoppen HO, Wintergalen N, Weitze KF, et al. 1995 Advanced ovulation in gilts by the intrauterine application of a low molecular mass pronase-sensitive fraction of boar seminal plasma. Journal of Reproduction and Fertility 105 247-252.

Waberski D, Claassen R, Hahn T, Jungblut PW, Parvizi N, Kallweit E \& Weitze KF 1997a LH profile and advancement of ovulation after transcervical infusion of seminal plasma at different stages of oestrus in gilts. Journal of Reproduction and Fertility 109 29-34.
Waberski D, Hunter RHF, Kremer H, Neto GB, Jungblut PW, Kallweit E \& Weitze KF $1997 b$ Induction of Ovulation with Seminal Plasma in Gilts - Investigation on the Local Signal Transduction. Reproduction in Domestic Animals 3210.

Waberski D, Kremer H, Borchardt Neto G, Jungblut PW, Kallweit E \& Weitze KF 1999 Studies on a local effect of boar seminal plasma on ovulation time in gilts. Zentralblatt Fur Veterinarmedizin. Reihe A $\mathbf{4 6}$ 431-438.

Watanabe H, Nagai K, Yamaguchi M, Ikenoue T \& Mori N 1993 Interleukin-1 beta stimulates prostaglandin E2 and F2 alpha synthesis in human ovarian granulosa cells in culture. Prostaglandins Leukotrienes, and Essential Fatty Acids 49 963-967.

Weiss TJ, Armstrong DT, McIntosh JE \& Seamark RF 1978 Maturational changes in sheep ovarian follicles: gonadotrophic stimulation of cyclic AMP production by isolated theca and granulosa cells. Acta Endocrinology (Copenhagen) 89 166-172.

Wuttke W, Pitzel L, Knoke I, Theiling K \& Jarry H 1997 Immuneendocrine interactions affecting luteal function in pigs. Journal of Reproduction and Fertility Supplement 52 19-29.

Received 30 December 2005

First decision 27 February 2006

Revised manuscript received 7 April 2006

Accepted 5 May 2006 